\title{
Experiencing Place: An Auto-ethnography on digging and belonging
}

\author{
STEVE BROWN
}

\author{
card left for \\ Mrs L. Weidenhofer. \\ Fairview Street. \\ Arncliffe \\ New South Wales.
}

$\mathrm{T}$

hese words appear on a card I recovered on 24 August 2007. It was the day I took ownership of the property at 85 Fairview Street in the Sydney suburb of Arncliffe, Australia. Though I did not know it at the time, the hand-written, pencilled and inked words were inscribed in 1938 prior to Mrs Weidenhofer's death. The marked card (Figure 1), perhaps formerly accompanying flowers, was one of many objects recovered from the sealed fireplace in the house's front

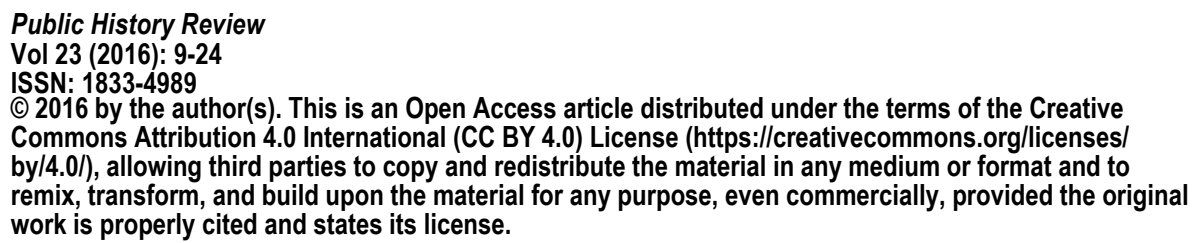


(bed)room. The cache of things, mixed amongst ash and charcoal, comprised three labelled pharmaceutical bottles - an antiseptic preparation for the treatment of whooping cough, Nyal corn remover and Marmola tablets for the treatment of obesity - a glass tube, an intact glass vase or ink pot, a fragment of a painted Chinese porcelain saucer, a glass doll's eye, a blackened ceramic marble, a disintegrated My Uncle Toby's Rolled Oats packet, a horse-race betting ticket and the card for Mrs Weidenhofer. As an archaeologist and new homeowner I was intrigued. Who was Mrs L. Weidenhofer? What gift accompanied the card? Why was the card entombed?

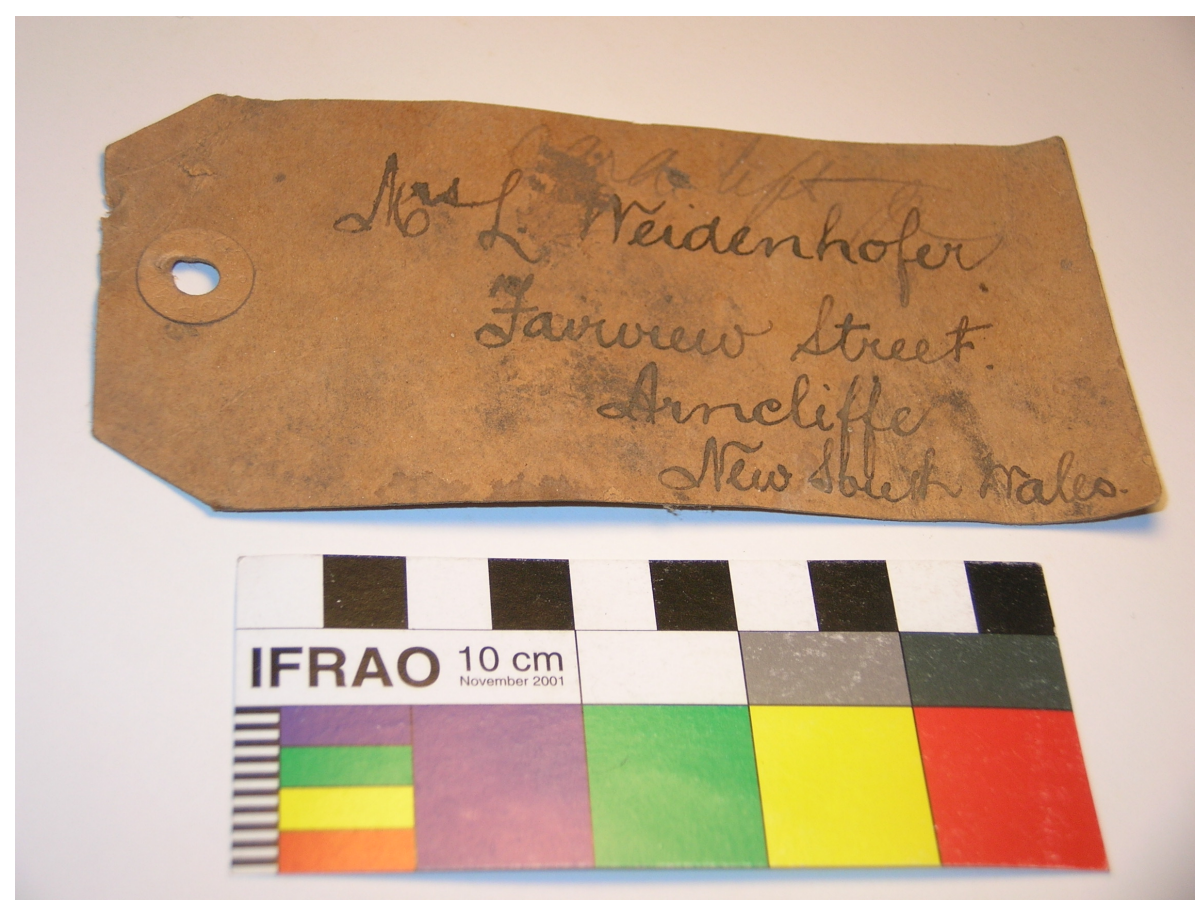

Figure 185 Fairview Street: 'Card left for Mrs L. Weidenhofer.' (Photograph Steve Brown, 2011)

I begin with the card encounter because this article is concerned with personal heritage and the role of material things in the construction of place-attachment. ${ }^{.}$My interest lies in interrogating my own sense of place-attachment (or belonging) to my home. I argue that personal experience can provide comparative information for investigating other peoples' experiences of their 'special places'. That is, by critically reflecting on my own connectivity to place I aim to gain a base-level of data that informs my understandings of other peoples' experiences of place; that is, the social values of heritage places and/or archaeological 
sites. ${ }^{2}$ I argue that self-awareness and reflexivity are important tools in the work of archaeologists who seek to recognise and respect personal and communal place-attachments.

As an archaeologist - I am trained in the practice and theories of archaeology - and a community member - I share expertise in, and feelings for, my local environment alongside other residents - I am in an ideal position to apply critical self-reflective or auto-ethnographic methods. Auto-ethnography is a method that focuses on cultural analysis and interpretation. It uses the researcher's autobiographical data to investigate the practice of others and employs reflection to develop analytic insights. ${ }^{3}$ The location where the application of autoethnography is most pertinent, and at which my double identity as archaeologist and community member coalesces, is my home. In this article I explore the phenomenon of identity from the perspective of the individual archaeologist as community member and memory elicited through experiences and provoked, invoked and creatively imagined through encounter and entanglement with the 'field site' - my home - and 'found objects' - that is, the 'card left for' Mrs Weidenhofer.

Thus my concern is not with memory and identity at the global, transnational or nation-state levels, but rather at the local scale of the single 'site' and 'small' landscape. My approach is personal and autobiographic, focussed on particular ways in which implicit and explicit memories that constitute human and object biographies become entangled and thereby construct knowledge of and elicit feelings for place. Because this piece is within a journal concerned with community, I begin with a discussion of the way in which I use the term.

\section{COMMUNITIES AS MORE-THAN-Human ASSEMBLAgeS}

'[T]he suburban block is replete with long evident family endeavour'.

Community is a slippery though usefully ambiguous term. The Macquarie Dictionary defines it as 'a group of any size whose members reside in a specific locality, share government, and have a cultural and historic heritage'. Laurajane Smith and Emma Waterton observe that while communities may be defined by place, shared histories and ethnicity, they 'take many forms, are often riven by dissent, and bear the burden of uncomfortable histories'. ${ }^{5}$ Furthermore, communities need not reside in a bounded geographic locality - such as the archaeological community is dispersed across the globe - share government - such as 
the European community of separate countries with individual governments - or have a common cultural heritage - like an on-line community. Thus no component of the Macquarie Dictionary definition is a necessary marker of a community. Additionally, communities need not be limited to the human estate. For example, ecological communities comprise interdependent collectives of plants and animals. In my view the latter includes humans, though this is not typically a view held by ecologists.

For the purpose of this article, I also want to stretch the meaning of community to include, but not be restricted to, material things. For example, I view the assemblage of objects recovered from the sealed fireplace at my home as a community of things. For 69 years the assemblage inhabited the fireplace. The view of collections of material things or objects as a community draws on post-human scholarship, an area of academic enquiry that views humans as part of - rather than separate from - the natural world and makes calls for greater equity between humans, other species and things. This view also draws on work in anthropology that emphasises the biography or social life of things, tracing an object throughout its 'lifecycle' from production, through various contexts of use and social efficacy, in order to emphasise its power to shape human affairs.' Social anthropologist Tim Ingold has argued for non-human things as active and alive; and for imagining a 'lifeworld' as a meshwork of interwoven lines whereby the relation between people and material things is 'a line along which materials flow, mix and mutate'. ${ }^{.}$Equally, in the field of material culture studies, political theorist Jane Bennett recognises things as vibrant and argues for 'vibrant matter' having a certain effectivity of its own.' Such thinking reveals how the material world has forms of power and agency that 'allow us to focus upon the way in which people and things are mutually related' ${ }^{10}$

By accepting ideas of 'things as active', I recognise communities of vibrant things as inseparable from the people who interact with them, whether in the past - such as the assemblage of objects concealed in the fireplace in1938 - or the present - my 'discovery' of the cache in 2007. That is, objects emerge from encounters with people and people's lives become entwined with objects. In anthropologist Daniel Miller's words: 'Things make us just as much as we make things.' Here Miller is making the point that people and things co-produce or co-create one another and are interdependent. Thus, a collection of objects is necessarily entangled with those people who create, utilise and discard them: communities of things become indivisible from communities of people. ${ }^{12}$ 
It is with the notion of communities as more-than-human assemblages in mind that I turn to consider the themes of this section: archaeologies of memory and identity. My attention is on interplays of past or historical people, and present-day humans, with material things. My focus is on the perspective of the archaeologist: the person who investigates a place through historical documents, interviews, field survey, excavation and, centrally, the material traces of place. But I also analyse the notion that, while archaeology has historically been about great discoveries, analytical techniques, accumulating knowledge and constructing interpretive frameworks, a less-considered aspect of archaeological practice is place-making and place-attachment. Archaeologist Sue Hamilton, for example, observes that archaeology, and excavation in particular, 'can engender a strong sense of, and reaction to, place'. . $^{13}$

\section{HOME-PLACE AND MATERIAL MemORY}

I present two narratives that serve to introduce my people/thing-based experience of place-attachment.

A woman and two children have escaped unhurt after shots were fired at their home in Sydney's south overnight. A number of bullets pierced the Arncliffe house just before $10 \mathrm{pm}$. Police spokeswoman Georgie Wells says forensic officers are examining the scene."

My home lies within the suburb of Arncliffe, eleven kilometres south of Sydney's CBD. Fairview Street, Arncliffe, was created in 1905 when two six-acre estates, Fairview and Belmont, were subdivided. The semidetached brick cottage at 85 Fairview Street was constructed by 1913. A Google search on 'Fairview Street Arncliffe', undertaken before I purchased and occupied number 85 , located media reports describing how the house had been fired upon at 10:20pm on Friday 17 February 2006. Local papers headlined reports on the incident with 'Family's home peppered with bullets' and 'Shots fired into Sydney home'. ${ }^{.5}$ The most obvious evidence of this violent episode is a hole, 11 millimetres in diameter, piercing the glass-panel above the front door. Radiating out from the bullet trace, across the glass, is a series of small cracks. On the inside of the glass pane, covering the hole, is a small (five centimetre diameter) circular sticker (Figure 2). The translucent sticker incorporates the Arabic character for Allah. I surmise that the Muslim family living here at the time deliberately covered the bullet hole with the sticker in order to propagate future blessings and safety from 
gunmen. I have left the sticker, not just because it covers the bullet hole in the glass, but also because it is a material memory of a dramatic event.

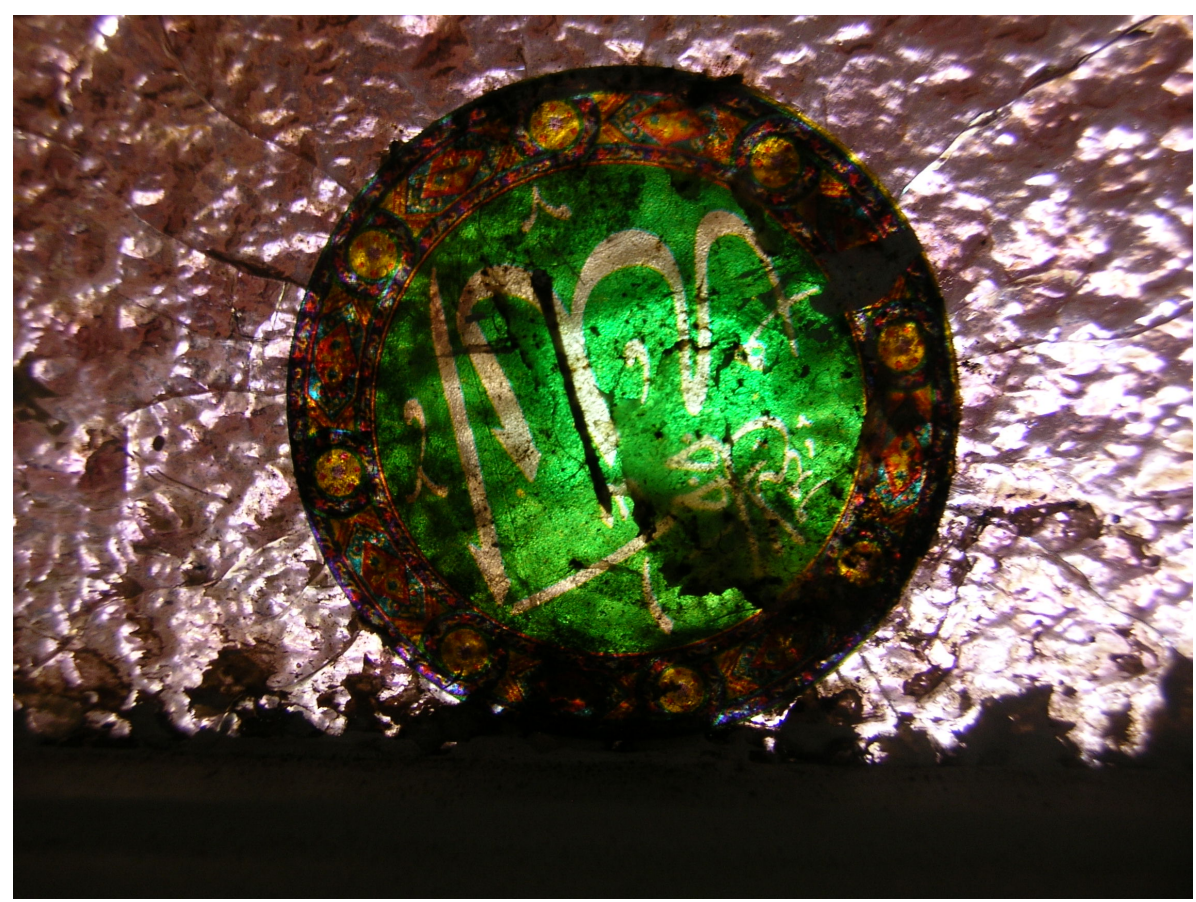

Figure 285 Fairview Street: sticker and bullet hole (Photograph Steve Brown, 2011)

Archaeology, according to archaeologist Laurent Olivier, is a discipline concerned with material memory. ${ }^{16}$ Rather than a form of history that emphasises sequential and linear time, Olivier argues, archaeology is a form of memory: 'Archaeological memory is a material memory'. ${ }^{.17}$ The material memory is unconscious and it is the role of the archaeologist, like the psychoanalyst, to bring to light something not immediately evident. In this view the past is not temporally or physically remote but rather is here, now and everywhere. Olivier states: 'the place of the past is not the past itself, but rather the present' ${ }^{18}$ Thus, in Olivier's conception, the discipline of archaeology is concerned with studying the materiality of the present regardless of whether material things originate in the deep or contemporary past; that is, time as multitemporal rather than linear. ${ }^{19}$

Olivier's reading of archaeology as practice in the present makes the discipline relevant to investigating contemporary identity and meaning. Returning to the bullet hole and sticker, I am faced with a choice of retaining the material things as static - though affective - representations 
of past events or transforming them by superimposing new narratives upon them. In fact the sticker has become overlain, for me, with new, personal meanings, one of which is that the tulip-shaped Arabic character acts as a metonym for my 2010 travels in Turkey, and in particular visits to Istanbul's Aya Sofya where huge nineteenth-century wood medallions inscribed with gilt Arabic letters, including the character for Allah, hang high above the marble floor. ${ }^{20}$ There is also an emotional dimension to this transformation - the bullet hole and sticker have become less a haunting reminder of danger and more a pleasurable memory of holiday travel. In other words, engagement with the material world is about transformational practice, an effect of which is to renovate place through personal experience and memory.

\section{BRINGING OBJECTS OUT OF THE GUTTER}

An archaeologist: a person who finds things, who resurrects objects from worlds that have disappeared and brings them back to the present, who goes forth with his eyes on the ground where the memory of eras gone by lies buried, who scans the surface of the earth, where time is recorded, in search of traces of the subtle workings of memory.21

My second narrative concerns a group of objects recovered in 2007 from the then leaf-filled gutter that extends along the front of the house. The assemblage comprises a 2005 twenty-cent piece (the coin commemorates 'Coming home' -60 years since the end of the Second World War), a set of grey plastic handcuffs with 'POLICE' embossed on each cuff and three toy sports cars. I find this assemblage tremendously evocative. I imagine the fun and frivolity of children at play, away from the gaze of parents, as they challenge each other to lob ever-more toys into the gutter. ${ }^{22}$ However, the two Fairview Street boys were not just any children, but rather the two shy boys who had huddled beside their mother on a lounge room sofa when, in June 2007, I inspected the house.

The gutter finds point to a boisterous and slightly naughty side to these children's behaviour and personalities. The toys mark a sense of performing boyhoods in which miniature fast cars, money and the long arm of the law appear as an innocent portrayal of adulthood, yet take place in the context of a house into which bullets were fired some eighteen months previously. Whatever the reality of the boys' lives and the story of the bullet hole, my material engagement with the toys and pierced glass panel draw out feelings and emotions that creatively, 
empathically and imaginatively connect me with place, and temporally with my own childhood. I envision and sense, but can never know, the lived-in, recent past.

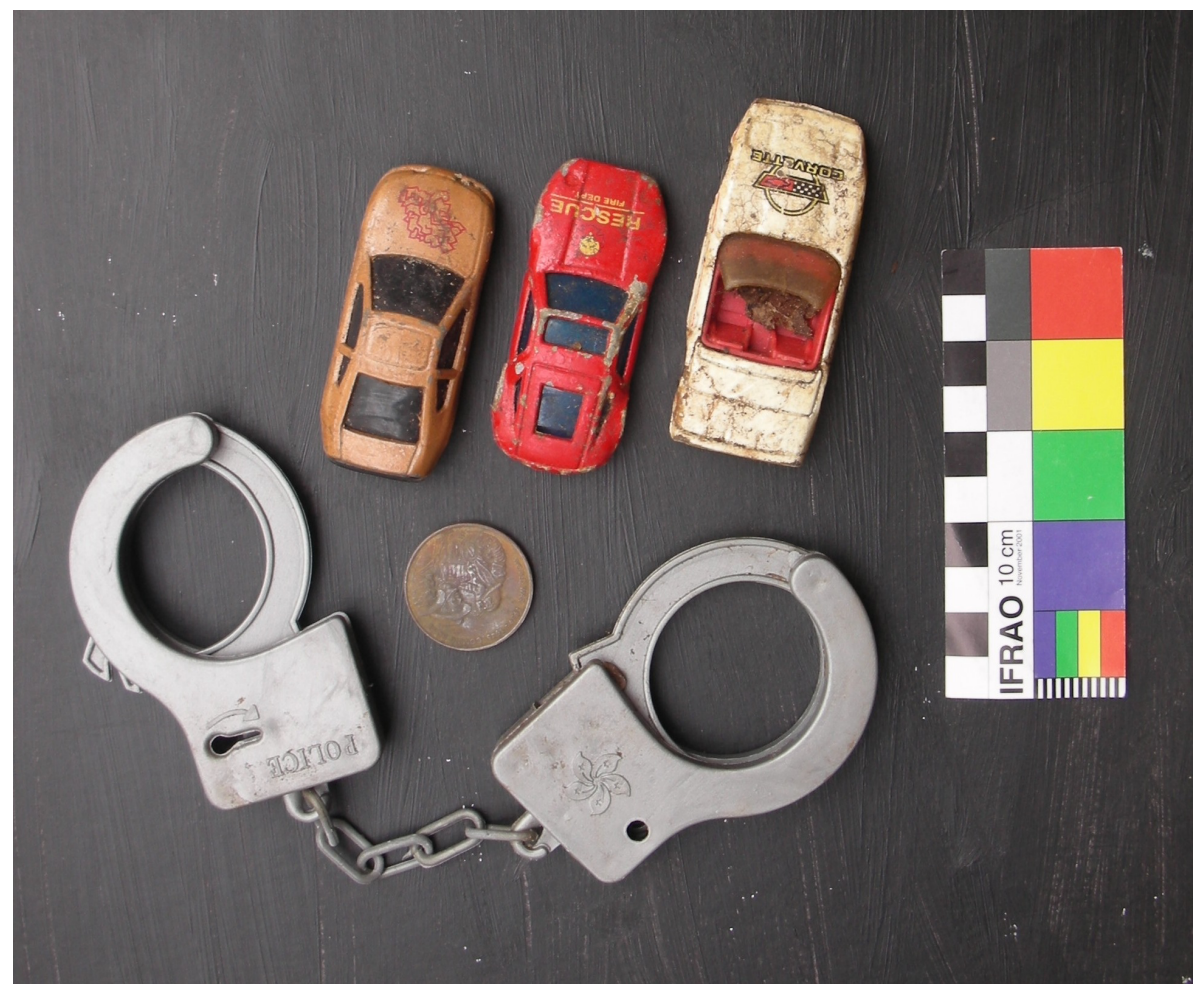

Figure 385 Fairview Street: gutter assemblage (Photograph Steve Brown, 2014)

In addition to the objects found in the house and gutter, I have encountered, through gardening, a vast amount of stuff, a world of things, at the Fairview Street property. ${ }^{.3}$ Fragments of glass, ceramic, metal, bone and plastics are common and occasionally I have encountered intact small bottles, marbles, beads, coins, buttons, animal teeth and plastic toy soldiers. Evidence of rubbish pits and lenses of discarded fireplace ash are occasionally unearthed whilst creating garden beds. I have encountered 'rare' finds: for example, an AirUK teaspoon, a handpainted gnome, a nineteenth-century clay pipe bowl and an Edward VII commemorative medallion. In singling out and privileging rare and exotic objects, I am participating in a practice that harks back to seventeenth-century European antiquarian traditions of assembling curiosities,,$^{24}$ a practice that in itself enables me to empathise with visitors to archaeological digs who might desire material evidence, a souvenir, of their visit. 
Between March 2010 and January 2011, I undertook six test-pit excavations across the Fairview Street property..$^{25}$ The excavations were provoked by the seemingly endless quantity of stuff recovered from establishing a garden. From an area of $5 m^{2}, 3600$ things were recovered and catalogued (Table 1), suggesting the presence of a total assemblage of 250,000 things buried across the $347 \mathrm{~m}^{2}$ suburban block. The massive quantity of material things points to all kinds of activities: evidence of the presence of children, women and men through things that have decayed, been abandoned and discarded or lost.

Table 185 Fairview Street test pit data

\begin{tabular}{|c|c|c|c|c|c|}
\hline TP no & Date & Location & $\operatorname{Size}(\mathrm{m})$ & Depth $(\mathrm{cm})^{*}$ & Total finds \\
\hline 1 & March 2010 & Backyard & $1 \times 1$ & 52 & 1182 \\
\hline 2 & April 2010 & Front yard & $1 \times 1$ & 45 & 545 \\
\hline 3 & July 2010 & Backyard & $1 \times 1$ & 39 & 879 \\
\hline 4 & Sept 2010 & Front yard & $1 \times 0.5$ & 30 & 85 \\
\hline 5 & Dec 2010 & Side of house & $2 \times 0.5$ & 32 & 320 \\
\hline 6 & Jan 2011 & Under house & $1 \times 0.5$ & 16 & 589 \\
\hline Totals & & & $5 \mathrm{~m}^{2}$ & $16-52$ & 3600 \\
\hline
\end{tabular}

So what might the bullet hole, sticker and gutter assemblage material traces that I have selected from amongst a huge array of found and excavated stuff - say about identity and memory and co-constituted communities of things and people?

\section{NARRATIVE, IDENTITY AND MEMORY}

My identity is entangled and interconnected with my home, and the memory-making that plays out within it. My home also happens to be an archaeological field site, where my life-history, other people's life-stories and vast numbers of object biographies intersect and become inextricably entangled. The archaeological deposits, the house fabric, the garden plantings - my body itself - are thick with embedded memory traces.

When reflecting on the feelings of living within this labyrinth of memory traces, I am reminded of a time when I went snorkelling whilst on a holiday in Bali. The dive site was an unbelievably beautiful location - when viewed from a distance. It was a bay of turquoise water with white-sand beaches fringed by forests of coconut palms. This idyllic tropical setting, however, was one where trails of refuse floated and 
sometimes sank into the waters of the bay. Every conceivable variety of plastic thing had been sucked out from a narrow creek mouth into the bay by a receding tide. Snorkelling through this viscous miasma of refuse and decay was unpleasant. Toothpaste containers and plastic shopping bags, as well as condoms and other nasties, occasionally brushed against my skin eliciting disgust at the rubbish and setting off my shark phobic angst.

My home of material vestiges and memory traces is generally not angst-ridden, like the snorkelling expedition, but still I am surrounded, enveloped and entangled within a world of material memories. Material things constantly brush against me, alert me to previous encounters, create new forms of engagement or simply become an everyday, barely noticeable, intra-action. In this regard I am drawn to the idea of material agency, ${ }^{26}$ a phenomenon that recognises the active participation of nonhuman forces in events: in Jane Bennett's terms, a 'vital materiality' that situates things as 'lively', 'the capacity of things...to act as quasi agents or forces with trajectories, properties, or tendencies of their own'.$^{27}$

Thus the bullet hole in the glass panel above the front door mostly goes unnoticed, outside of conscious awareness, on my many-daily trips along the entry hall toward the front door. Sometimes, however, I mindfully glance up at the sticker and bullet hole, where memories of shooter and holidays come to the fore, re-experienced in bodily and affective ways and with varying intensity. The presence of the bullet trace and the violence it projects is particularly powerful when other drive-by shootings at private residences are reported in the media. ${ }^{28}$

In memory research the neurobiological explanation for the effect of an initial experience on the brain is termed an engram. ${ }^{29}$ Thus in my initial entanglements with the bullet hole and sticker, my engram included various levels of experience: semantic or factual - my knowledge of the origin of the bullet hole; autobiographical - my sense of self at the time I recognised the trace to be a bullet hole); somatic - what my body felt like; perceptual - what the bullet hole looked and felt like; emotional my mood at the time; and behavioural - what I did with my body. My original bullet hole engram includes linkages connecting each of these forms of representation. My subsequent encounters with the bullet hole draw on, but never fully replicate, these various initial experiential levels because explicit memory is cumulative rather than repetitive. ${ }^{30}$

Thus when I said that material things constantly 'brush' against me in my home, I mean there is a complex interplay occurring between different experiential levels of remembering in addition to the liveliness, or vital materiality, of the things, the bullet hole and sticker, themselves. I choose to conceptualise such encounters within a paradigm of co- 
production and co-enactment that focuses on entanglement: that is, entanglement across assemblages of people-places-things rather than interactions of pre-existing, separate entities. ${ }^{31}$ An explanatory framework of entanglement between humans, non-humans and materials is as much applicable to the bullet hole and the gutter assemblage as it is to other forms of archaeological assemblages.

Much of my personal identity is entangled with the abstract notion of home, a complex construction of spatially situated materials and memories. For me, home as abstract entity is constructed and performed through innumerable individual experiences and events that are tied to place and to physical fabric, found objects and material traces. The narratives of the bullet hole and gutter assemblage are nested within larger stories - for example, the story of the residency of the family who occupied 85 Fairview Street before I purchased and moved into the place. My home-place is infused and enlivened with material traces, with communities of things.

This point is evidenced in a family archaeology project undertaken by Jonna Ulin, who describes her excavation and memory-work at 'Per Johan's place', her grandmother's house in Sweden. ${ }^{33}$ Ulin's autoethnographic account - which Ulin calls 'exploring the walkscape of my biographical past' - draws from excavated materials, childhood recollections and family stories, secrets and photographs. ${ }^{34}$ This mixed data assemblage is a reminder that all people, places and things have material, storied and familied pasts. Thus when archaeologists investigate and excavate houses, even when not their own, they are entering spaces filled and alive with memories. The memories are, firstly, materially enfolded into the ruins and sediments themselves and, secondly, held by present-day people who know the place in its current landscape setting. The archaeologist, against the personal backdrop of his/her own experience of house as home, typically investigates in situ material memories and listens to local community stories. Hence my argument at the start of this article that self-awareness and reflexivity are important tools in the work of archaeologists who seek to recognise and respect other people's and communities' knowledge, experience and place-attachments.

\section{CONCLUSION: ENVISIONIng COMMUNITY MeMBeRS AS ARCHAEOLOGISTS?}

What are the implications of this personalised account of home, identity and memory for the work of archaeology and heritage practice more generally? The major point I make harks back to the seminal edited volume Writing Culture by James Clifford and George Marcus. ${ }^{35}$ In 
essence the collective message of that book's authors focuses on the authority of the ethnographic text. The authors question established modes of ethnographic writing that embody a single authorial voice and thereby, they argue, privilege the ethnographer as expert. The alternative is a dialectical and dialogical ethnography that incorporates, even privileges, multiple meanings of place as expressed by other, nonarchaeologist, communities and individuals. Yannis Hamilakis terms such an approach archaeological ethnography, which includes a concern for investigating the social and public contexts of archaeology and the ways archaeological knowledge is constructed. ${ }^{36}$

My point is that an archaeologist who undertakes research via field studies for the purpose of knowledge-making is at one and the same time an observer and a participant. As Sue Hamilton notes, for archaeologists, fieldwork engenders a strong sense of, and reaction to, place. The bodily experience of landscape, the affective entanglements with sediments and artefacts, the complex memory engrams associated with uncovering things and features and the ways in which objects are invested with mnemonic significance must necessarily inform the ways in which meaning is attributed to, in Olivier's words, 'studying the materiality of the present'. The identities and memories, spatialised within the context of the field site, will always remain an implicit part of archaeological field experience and therefore should necessarily, in my view, be made explicit in the construction of place narratives. Autoethnography that critically reflects upon the entangled memories of place and archaeological objects is a valuable methodology and practice in this regard.

Framed in a different way, I suggest that archaeologists occupy a powerful and privileged position: they exercise enormous control over memory and identity through ways in which stories of the past are told. We construct archives of the past, that is, what is retained, how it is sorted and catalogued, and the narratives constructed about specific objects, places, people and events. As historians Joan Schwartz and Terry Cook remind us, archivists - and here I include archaeologists, historians and heritage practitioners - have a powerful mediating role in shaping recorded memory by determining what is preserved and made accessible..$^{37}$ In this way, place, identity and memory are dynamic and there is rarely ever one narrative, even with regard to bullet holes and assemblages of children's toys.

Through my personal, auto-ethnographic investigation of homeplace attachment I have learned that community member and archaeologist are difficult-to-separate identities. My local community arises from my entanglements with friends, neighbours, previous 
(historicised) residents - such as Mrs Weidenhofer - and vibrant objects, including a card, bullet trace, sticker and childhood toys. I have found comfort in resisting the objectivity associated with the expertise of the archaeologist and heritage practitioner and found great pleasure and reward in sensuous engagement with the genealogies, social lives and material memories of things. I have learnt that when I enter new landscapes to perform archaeological or heritage tasks, I am necessarily choosing to become part of, rather than consult or objectively study, local communities of people and things.

Michael Shanks observes that 'we are all archaeologists now'. What Shanks' notion points to is that all people engage with places in archaeological ways when they encounter things and creatively think about them. ${ }^{38}$ If we are all archaeologists in our various ways, then the idea that archaeologists and community members are necessarily separate identities is dissolved to a considerable degree. That all community members are archaeologists and all archaeologists are members of communities is a concept I find useful in my work in archaeological and heritage practice.

\section{POSTSCRIPT: MRS WEIDENHOFER AND ME}

Having introduced Mrs L. Weidenhofer via an entombed card at the start of this paper, I feel it incumbent upon me to share something of my knowledge of her. In so doing I will briefly respond to the questions: Who was Mrs L. Weidenhofer? What gift accompanied the card? Why was the card entombed?

Some facts. Mrs L. Weidenhofer is Winifred Nina Flood. Winifred was born on 22 December 1886 at Narrandera, a small country town on the Murrumbidgee River in southern New South Wales, Australia. In 1908, at age 22, Winifred married Laurence Miller Weidenhofer (b1883) and together they had four children. In 1920, the family moved into 85 Fairview Street, Arncliffe. In the Australian Electoral Rolls of the 1930s, Winifred's occupation is listed as 'home duties' and Laurence's as 'carpenter'. They remained as tenants at the cottage until Winifred's death at age 52 in July 1938.

Some speculation. Perhaps Winifred succumbed to whooping cough as evidenced by the 'eucresol inhalant' medicine bottle recovered from the bedroom fireplace. Perhaps the pencilled and inked 'card left for Mrs L. Weidenhofer' accompanied flowers that shared the final days of her life. Perhaps she died in my bedroom. The landlord of the Fairview Street property at the time of Winifred's death was Clarence Roy Tasker, a market gardener. He likely blocked-in the front room fireplace prior to 
re-letting the property: Laurence had moved out soon after Winifred's passing. In the process, Winifred's card and the final discarded traces of family life, death and grief were gathered and deposited into the hearth space. Perhaps this was a deliberate act of cleansing the space.

Some feelings. The card, recovered 69 years after Winifred had died and Clarence Tasker had sealed it in a disused fireplace, is an object that has great power, a potent object. The card was one of the first objects I encountered in the house. It drew me into the object world of my home and called on me to speculate on its social life, investigate its factual history and create a fragmentary narrative. The card alerted me to the history of my home and the card and I became entangled in my homemaking enterprise. The card and its associated assemblage, Winfred and her family and me are, to my mind, a community of entangled things. Happily entangled things.

\section{ACKNOWLEDGEMENTS}

I thank the section editors Tracy Ireland and Jane Lydon for encouraging me to attend the SHA 2014 Quebec City meeting and to participate in the session they chaired on archaeologies of memory and identity. I thank Jane, Tracy, Annie Clarke, Ralph Mills and Erin Gibson for conversations arising out of the SHA paper. I thank Jane Lydon and Annie Ross for their constructive feedback on and review of this article.

\section{ENDNOTES}

1 Steve Brown, 'Place-attachment in Heritage Theory and Practice: A Personal and Ethnographic Study', PhD dissertation, The University of Sydney, 2015.

2 In the field of heritage practice, Randall Mason suggests that value is 'a set of positive characteristics or qualities'. That is, a value is a culturally ascribed meaning or quality attributed by individuals and/or cultural groups to a heritage object, place or landscape. Randall Mason, 'Assessing values in conservation planning: methodological issues and choices', in Marta de la Torre (ed), Assessing the Values of Cultural Heritage: Research Report, The Getty Conservation Institute, Los Angeles, 2002, pp5-30.

3 Heewon Chang, Autoethnography as Method, Left Coast Press, Walnut Creek, California, 2008; Elijar Anderson, 'Jelly's place: an ethnographic memoir', in Dick Hobbs and Richard Wright (eds), The Sage Handbook of Fieldwork, Sage, London, 2006, pp39-58.

4 David Trigger, 'Place, belonging and nativeness in Australia', in Frank Varclay, Matthew Higgins and Adam Blackshaw (eds), Making Sense of Place, National Museum of Australia, Canberra, 2008, p302.

5 Laurajane Smith and Emma Waterton, Heritage, Communities and Archaeology, Duckworth, London, 2009, p24.

6 Vered Amit and Nigel Rapport, The Trouble with Community: Anthropological Reflections on Movement, Identity and Collectivity, Pluto Press, London, 2002.

7 Igor Kopytoff, 'The cultural biography of things: commoditization as process', in Arjun Appadurai (ed), The Social Life of Things: Commodities in Cultural Perspective, Cambridge University Press, Cambridge, 1986, pp64-91. 
8 Tim Ingold, 'Materials against materiality', Archaeological Dialogues, vol 14, no 1, 2007, pp1-16.

9 Jane Bennett, Vibrant Matter: A Political Ecology of Things, Duke University Press, Durham and London, 2010, ppviii-xiii.

10 Andrew M. Jones and Nicole Boivin, 'The malice of inanimate objects: material agency', in Dan Hicks and Mary C. Beaudry (eds), The Oxford Handbook of Material Culture Studies, Oxford University Press, Oxford, 2010, pp291-309.

11 Daniel Miller, Stuff, Polity, Cambridge and Malden, 2010.

12 Ian Hodder, Entangled: An Archaeology of the Relationships between Humans and Things, Wiley-Blackwell, West Sussex, 2012.

13 Barbara Bender, Sue Hamilton and Chris Tilley, Stone Worlds: Narrative and Reflexivity in Landscape Archaeology, Left Coast Press, Walnut Creek, California, p66.

14 ABC News, 'Shots fired into Sydney home', 2006, http:/ / www.abc.net.au/news/stories/2006/02/18/1572980.htm accessed 26 June 2009.

15 ibid.

16 Laurent Olivier, The Dark Abyss of Time: Archaeology and Memory, (translated by Arthur Greenspan) AltaMira Press, Lanham, 2011. Colin Renfrew views material memory as 'perpetual engagement', a notion that consciously harks back to Igor Kopytoff's insights into the life-histories of artefacts. See Colin Renfrew, 'Towards a theory of material engagement', in Elizabeth DeMarrais, Chris Gosden and Colin Renfrew (eds), Rethinking Materiality: The Engagement of Mind with the Material World, McDonald Institute of Archaeological Research, Cambridge, 2004, pp23-32; Kopytoff, op cit.

17 Olivier, op cit, p59.

18 Olivier, op cit, p86.

19 Yannis Hamilakis, 'Archaeological ethnography: A multitemporal meeting ground for archaeology and anthropology', Annual Review of Anthropology, vol 40, 2011, pp399-414. See also Thomas D. Andrews and Susan Buggey, 'Authenticity in Aboriginal cultural landscapes', APT Bulletin, vol 39, nos 2/3, 2004, pp63-71; Denis Byrne, 'Messages to Manilla', in Ingereth A.S. Macfarlane with Mary-Jane Mountain and Robert Paton (eds), Many Exchanges: Archaeology, History, Community and the Work of Isabel McBryde, Aboriginal History Monograph 11, 2005, pp53-62;

Rodney Harrison, 'Surface assemblages: towards an archaeology in and of the present', Archaeological Dialogues, vol 18, no 2, 2011, pp141-161.

20 A powerful memory of the visits is discovering and tracing marks cut into the marble floor that outline the circumference of the main dome that soars above. Looking upward to the dome is a large part of the tourist experience, examining the floor something more suited to the archaeological gaze.

21 Olivier, op cit, p3.

22 I recall doing something similar in my youth, an episode when my friends and I lobbed thongs (or flip-flops) ever higher into a tree.

23 Stuff: a broad category that considers material things as well as plant and animal species as artefacts. See Miller, op cit.

24 Gavin Lucas, 'Fieldwork and collecting', in Dan Hicks and Mary C. Beaudry (eds), The Oxford Handbook of Material Culture Studies, Oxford University Press, Oxford, 2010, p230-235. See also Tom Griffiths, Hunters and Collectors: The Antiquarian Imagination in Australia, Cambridge University Press, 1996.

25 Steve Brown, 'Toward an archaeology of the twentieth-century suburban backyard', Archaeology in Oceania, vol 47, no 2, 2012, pp99-106.

26 Jones and Boivin, op cit.

27 Bennett, op cit, pviii.

28 Drive-by shootings at private residences, or drive-bys (a local vernacular term), were virtually unheard of in Sydney in the mid-1990s but grew, for example, in the first half of 2013 to 72 shootings or one every $2 \frac{1}{2}$ days. See for example I. L. Neubauer 'In Sydney, disaffected Lebanese kids caught in spiralling gang 
violence', Time World, 11 October 2013. Police and media reports attribute drive-bys to ethnic rivalries (such as, conflict between Sunni and Shia religious factions), bikie turf wars, drug-related disputes of organised crime gangs, tit-for-tat matters between family members and 'copycats'. See N. Ralston and G. Kwek, '100 shootings and counting: Merrylands tops drive-by list', Sydney Morning Herald, 11 September 2012. The extent of this urban landscape of drive-bys is visible in various cartographic representations of drive-by shooting locations. See for example L. Phillips, 'Sydney shootings', 2012,

https: / / maps.google.com.au / maps / ms?ie=UTF8\&oe=UTF8\&msa=0\&msid=20578 6830198022339085.0004b6474e0143d95e33d accessed 10 January 2014.

29 Daniel J Siegel, The Developing Mind: How Relationships and the Brain Interact to Shape Who We Are, Second Edition, The Guilford Press, New York and London, 2012, p50.

30 ibid, pp50-51.

31 Karen Barad, Meeting the Universe Halfway: Quantum Physics and the Entanglement of Matter and Meaning, Duke University Press, Durham and London, 2007, pp183185.

32 Hodder, op cit; Ingereth A.S. Macfarlane, 'Entangled Places: Interactive Histories in the Western Simpson Desert', Central Australia, PhD dissertation, The Australian National University, 2010.

33 Jonna Ulin, 'In the space of the past: a family archaeology', in Cornelius Holtorf and Angela Piccini (eds), Contemporary Archaeologies: Excavating Now, Peter Lang, Frankfurt am Main, 2009, pp145-159.

34 ibid, p145.

35 James Clifford and George E. Marcus (eds), Writing Culture: The Poetics and Politics of Ethnography, California University Press, Berkeley and Los Angeles, 1986.

36 Hamilakis, op cit.

37 Joan M. Schwartz, 'Complicating the picture: place and memory between representation and reflection', in James Opp and John C. Walsh (eds), Placing Memory and Remembering Place in Canada, UBC Press, Vancouver, 2010, p302. 38 Michael Shanks, The Archaeological Imagination, Left Coast Press, Walnut Creek, California, 2012, p42. 